\title{
Immunohistochemical quantitation of oestrogen receptors and proliferative activity in oestrogen receptor positive breast cancer
}

\author{
V Jensen, $M$ Ladekarl
}

\begin{abstract}
Aim-To evaluate the effect of the duration of formalin fixation and of tumour heterogeneity on quantitative estimates of oestrogen receptor content (oestrogen receptor index) and proliferative activity (MIB-1 index) in breast cancer.

Methods-Two monoclonal antibodies, MIB-1 and oestrogen receptor, were applied to formalin fixed, paraffin wax embedded tissue from 25 prospectively collected oestrogen receptor positive breast carcinomas, using a microwave antigen retrieval method. Tumour tissue was allocated systematically to different periods of fixation to ensure minimal intraspecimen variation. The percentages of MIB-1 positive and oestrogen receptor positive nuclei were estimated in fields of vision sampled systematically from the entire specimen and from the whole tumour area of one "representative" cross-section.
\end{abstract}

Results-No correlation was found between the oestrogen receptor and MIB-1 indices and the duration of formalin fixation. The estimated MIB-1 and oestrogen receptor indices in tissue sampled systematically from the entire tumour were closely correlated with estimates obtained in a "representative" section. The intraand interobserver correlation of the MIB-1 index was good, although a slight systematical error at the second assessment of the intraobserver study was noted.

Conclusion-Quantitative estimates of oestrogen receptor content and proliferative activity are not significantly influenced by the period of fixation in formalin, varying from less than four hours to more than 48 hours. The MIB-1 and the oestrogen receptor indices obtained in a "representative" section do not deviate significantly from average indices determined in tissue samples from the entire tumour. Finally, the estimation of MIB-1 index is reproducible, justifying its routine use.

(f Clin Pathol 1995;48:429-432)

Keywords: Breast cancer, MIB-1, oestrogen receptor, proliferative activity.

Immunohistochemical analyses of oestrogen receptor status and proliferative activity are of prognostic value in breast cancers. ${ }^{1-4}$ Moreover, oestrogen receptor analysis offers a method for the prediction of response to endocrine therapy. ${ }^{56}$ Until recently, these methods have required fresh material. The development of antibodies that can be used on formalin fixed, paraffin wax embedded material for the evaluation of the oestrogen receptor status and proliferative activity permits direct comparison with morphological and morphometrical variables.

The monoclonal antibody MIB-1 reacts with the Ki67 nuclear antigen ${ }^{78}$ associated with cell proliferation and found throughout the cell cycle (G1, S, G2, and $M$ phases), but not in resting (G0) cells. A previous study has shown MIB-1 as a robust marker of cell proliferation and that a clear plateau effect is easily discerned. ${ }^{8}$ On paraffin wax embedded tissue sections, using a microwave antigen retrieval method, the MIB-1 antibody gives an immunohistochemical staining pattern which is identical with that of the Ki67 antibody in frozen sections. ${ }^{79}$ This antigen retrieval method, first described by Shi et al, ${ }^{10}$ also permits subsequent staining with monoclonal antibody to oestrogen receptor.

In previous studies of breast cancer the percentage of oestrogen receptor positive cells ${ }^{611-13}$ and proliferating cells ${ }^{1214-16}$ varied considerably. Among the possible explanations for the discrepancies are sampling variation, intratumoral heterogeneity, different nature of the tumour samples (fresh, frozen or fixed tissue), variable dilution of antibody, differences in counting methods, and observer variability in the interpretation of the staining. In addition, immunostaining of formalin fixed tissue may be influenced by the duration of fixation, ${ }^{1718}$ which is often an unknown variable in archival material. In the present study, we evaluated the effect of the duration of formalin fixation on estimates of the percentage of oestrogen receptor positive and MIB-1 positive cells obtained in tissue from 25 prospectively collected, oestrogen receptor positive breast carcinomas. A minimal intraspecimen variation of estimates was ensured by an efficient design of systematic random tissue sampling. ${ }^{19}$ This design also enabled the evaluation of the influence of tumour heterogeneity on the variables by comparing estimates obtained from the entire tumour with those obtained in a "representative" tumour section. Finally, the intra-and interobserver reproducibility of estimates of the percentage of MIB-1 positive cells was investigated. 


\section{Methods}

Twenty five oestrogen receptor positive breast carcinomas, resulting in five or more slices when cut as described below, were prospectively included in the study. Tissue processing was performed as described in detail by Ladekarl ${ }^{20}$ Briefly, each tumour was isolated from the surrounding fatty tissue and cut into $2 \mathrm{~mm}$ thick, parallel slices, of which every second was used for routine analyses. The remaining slices (every second) were used for further investigations and cut into bars, $2 \mathrm{~mm}$ thick. Specimens were, in general, fixed within 15 minutes of removal for at least 48 hours in $10 \%$ formalin at room temperature. However, to investigate the influence of different periods of fixation, tumour bars from nine carcinomas were allowed to fix for two to four hours, four to 24 hours, 24 to 48 hours, and 48 to 166 hours, respectively. In all steps tissue sampling was performed randomly ${ }^{19}$ - that is, every nth of the items (slices or bars) was sampled systematically starting at a random number between one and $n$. After fixation, the tissue was embedded in paraffin wax using standard procedures. From each of the blocks containing systematically sampled tumour bars and from a paraffin wax embedded, "representative" slice selected for routine evaluation, $3 \mu \mathrm{m}$ thick sections were cut and placed on electrostatic treated slides and air-dried overnight at room temperature.

Immunostaining was performed using oestrogen receptor antibody (Dako, Glostrup, Denmark) and MIB-1 antibody (Immunotech, Marseille, France). Sections were stripped of paraffin in xylene, rehydrated through graded alcohols, and incubated three times for five minutes each in citrate buffer $(\mathrm{pH}=6.0)$ in a household microwave oven at $800 \mathrm{~W}$. The slides were then allowed to cool down to room temperature, were washed briefly with Tris buffered saline (TBS) $(\mathrm{pH}=7 \cdot 4)$ and incubated for 20 minutes with $3 \%$ hydrogen peroxide in water to block endogenous peroxidase activity. Oestrogen receptor and MIB-1 antibodies were used at 1 in 75 and 1 in 100 dilutions, respectively, for 30 minutes at room temperature. Biotinylated mouse/rabbit antibody (Dako) at a dilution of 1 in 100 was used as the linker molecule. Finally, after washing, avidin-biotin complex (Dako) was applied and aminoethylcarbazole was used for visualisation.

A known oestrogen receptor positive breast carcinoma was included as the positive control and as the negative control, the oestrogen receptor antibody was replaced by TBS. For each MIB-1 staining run, a lymph node with reactive germinal centre cells served as a positive control

Mean and coefficient of variation (CV) of the oestrogen receptor and MIB-1 indices obtained at different fixation times $(n=9)$

\begin{tabular}{lcccc}
\hline \multicolumn{5}{c}{ Fixation time (hours) } \\
\cline { 2 - 5 } Index & $2-4$ & $4-24$ & $24-48$ & $48-166$ \\
\hline MIB-1 & 30 & 35 & & \\
mean (\%) & 0.46 & 0.37 & 31 & 33 \\
CV & 76 & 77 & 0.41 & 0.39 \\
$\begin{array}{l}\text { Oestrogen receptor } \\
\text { mean (\%) }\end{array}$ & $0 \cdot 21$ & 0.23 & 76 & 75 \\
CV & & & 0.27 & 0.24 \\
\hline
\end{tabular}

and peripheral nerve tissue served as the negative control. The sections were evaluated blindly in a random sequence at high magnification $(\times 1100,60 \times$ oil immersion lens) using a standard microscope with a projection attachment (Olympus Danmark, Glostrup, Denmark). In each case a median number of 14 fields of vision (range, 8-43) was sampled systematically by moving a fixed distance between fields through the centre of the sectioned bars, along the long axis. The position of the first field of vision was at random from the top of the sectioned bar. An average of 352 tumour cells (range, 97-892) were counted, using a counting frame and an unbiased counting rule. ${ }^{21}$ Highly inflamed and necrotic areas were avoided and only infiltrating tumour cells were evaluated. Tumour cells were considered to be positive for oestrogen receptor and MIB-1 if nucleoplasm or nucleoli were stained regardless of its intensity. The oestrogen receptor and MIB-1 indices were calculated as the percentage of positive tumour cell nuclei. The time spent evaluating each tumour was, on average, 15 minutes.

Finally, the oestrogen receptor and MIB-1 indices were estimated in a "representative" section from each tumour, containing both tumour margin and a central area, selected from the slices used for routine analyses. In these cases a minimum of 10 fields of vision (median 15) were chosen randomly from the whole section, counting an average of 278 tumour cells (range, 136-676) per specimen.

\section{STATISTICAL ANALYSES}

Mean and coefficient of variation of oestrogen receptor and MIB-1 indices were calculated. The correlation between the indices obtained at different fixation times as well as the influence of tumour heterogeneity and observer correlation were investigated by least-square linear regression. However, because of the discontinuous distribution of oestrogen receptor indices, the influence of tumour heterogeneity on these was investigated by Kendal's $\tau$ test; ${ }^{22}$ $2 p<0.05$ was considered significant.

\section{Results}

The mean tumour diameter was $27 \mathrm{~mm}$ (range, 14-50 mm). Eighteen patients were postmenopausal and seven premenopausal. Concerning both antibodies, considerable heterogeneity was observed with respect to the intensity of nuclear staining in adjacent cells within the same region and in different cell groups. The MIB-1 index ranged between 6 and $57 \%$, whereas the oestrogen receptor index ranged between 14 and $95 \%$.

Data for oestrogen receptor and MIB-1 indices obtained in tissue samples fixed in buffered formalin for four different periods are shown in the table. The regression analyses did not show a significant correlation between the mean of estimates and the storage period $(2 p \geq 0 \cdot 20)$.

As illustrated in the figure, the indices estimated in bars sampled systematically from 


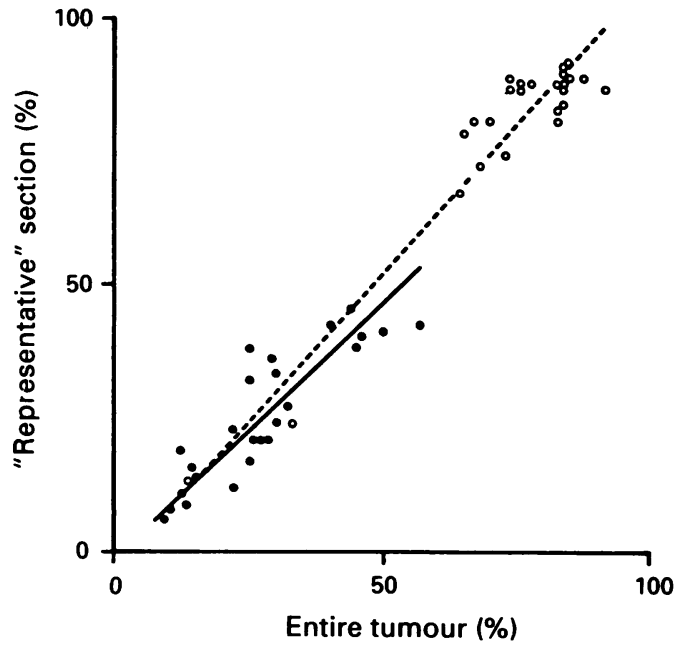

Oestrogen receptor and $M I B-1$ indices obtained in a "representative" section plotted against indices obtained from the entire tumour $(n=25)$. $O, M I B-1$ index; $\bigcirc$, oestrogen receptor index. MIB-1: slope of correlation line $(=0.93)$ and ordinate intersection $(-0.001 \%)$ did not deviate significantly from unity and zero, respectively. Oestrogen receptor values were not analysed by linear regression because of the very skewed distribution of the data. However, the correlation line is shown for comparison.

the entire tumour were closely correlated with indices obtained in the "representative", routinely processed section $(r=0.88$ and $\tau=$ 0.79 for MIB-1 and oestrogen receptor indices, respectively). The interobserver reproducibility of the MIB-1 index was good $(r=0.82$; the slope of the correlation line and the intersection with the ordinate were not significantly different from unit and zero, respectively). The intraobserver correlation (two sets of estimates obtained three months apart) was excellent ( $r=$ 0.92 ), but the intersection with the ordinate was $9 \%$, indicating a slight systematic error $(2 \mathrm{p}=0.03)$.

\section{Discussion}

Formalin fixation may not always be the best choice for preserving tissue antigenicity for immunohistochemical procedures. The process is relatively slow (about $0.8 \mathrm{~mm}$ tissue penetration per hour ${ }^{23}$ ) and if the specimen is large, the central part may be insufficiently fixed. In the present study fixation was performed almost immediately and tissue was cut small to ensure quick and adequate fixation. Using this procedure, we found that oestrogen receptor and MIB-1 indices were not greatly influenced by increasing the period of formalin fixation from less that four hours to more than 48 hours. It has been reported that prolonged exposure to formalin diminishes immunoreactivity of proliferation associated nuclear antigens ${ }^{17}$ and oestrogen receptors. ${ }^{18}$ Technical differences regarding - for example, specimen thickness, enhancement procedure and the antibody/antigen/epitope detected may explain the conflicting results.

In view of the intratumoral heterogeneity with respect to oestrogen receptor content ${ }^{24}$ and proliferative activity, ${ }^{131425}$ it is obvious that several fields must be analysed. In the present study, the proliferative activity and oestrogen receptor content were determined in fields of vision sampled systematically and randomly from the entire tumour. The use of a clearly defined sampling technique and the evaluation of immunoreactivity in multiple systematically selected fields of vision from the entire tumour provides an effective control against intratumoral heterogeneity and ensures reproducible results. However, the present study indicates that systematic sampling of fields of vision from a single "representative" tumour slice may be sufficient for accurate determination of the oestrogen receptor status and the proliferative activity of the entire specimen.

A commonly used method for quantitation of immunohistochemically determined oestrogen receptors is the HSCORE developed by McCarty et al. ${ }^{2627}$ This method incorporates both the proportion and intensity of specific, positively staining tumour cells. However, we find it difficult to grade the straining intensity in heterogeneous tumour tissue in an objective and reproducible manner, while the question of whether staining is positive or not is easier to settle. However, even in this case, the systematic differences between the two assessments of the same observer indicates that the threshold, at which a particular cell is termed "positive", is a subjective component inherent in the evaluation technique. Fortunately, this difference is small compared with the large variation between the patients (coefficient of variation, $40 \%$ ). In view of the very skewed distribution of the oestrogen receptor indices (median oestrogen receptor index = $86 \%$ ), the prognostic value of the immunohistological quantitation of oestrogen receptor content needs to be examined in a large prospective study with appropriate clinical follow up.

Using immunohistochemical techniques with an antigen retrieval method and microscopic evaluation of systematically selected fields of vision, the following may be concluded: (1) quantitative estimates of the oestrogen receptor content and the MIB-1 percentage are not significantly influenced by the period of fixation in formalin; (2) the MIB-1 and oestrogen receptor indices obtained in one "representative" tumour section closely correlate with indicates determined in several tissue samples from the entire tumour; and (3) estimation of the MIB-1 index is reproducible and may be suitable for routine purposes.

The authors thank Dr F Melsen, Institute of Pathology, Århus Amtssygehus, University of Ârhus, for critical review of the Amtssygehus, University of Arhus, for critical review of the
manuscript and Dako A/S, Denmark for the gift of antibody to manuscript and Dako A/S, Denmark for the gift of antibody to
oestrogen receptor. The study was supported by The Danish Cancer Society.

1 Barnard NJ, Hall PA, Lemoine NR, Kadar N. Proliferative index in breast carcinoma determined in situ by Ki67 immunostaining and its relationship to clinical and immunostaining and its relationship to clinica

2 Sampson SA, Kreipe H, Gillett CE, Smith P, Chaudary Sampson SA, Kreipe H, Gillett CE, Smith P, Chaudary
MA, Khan A, et al. KiSI - a novel monoclonal antibody which recognizes proliferating cells: evaluation of its relationship to prognosis in mammary carcinomas. $f$ Pathol 1992;168:179-85.

3 Wintzer HO, Zipfel I, Schulte-Mønting J, Hellerich U, Von Kleist. Ki-67 immunostaining in human breast tumors and its relationship to prognosis. Cancer 1991;67:421-8. 4 Tahan SR, Neuberg DS, Dieffenbach A, Yacoub L. Pre- 
diction of early relapse and shortened survival in patients with breast cancer by proliferating cell nuclear antigen score. Cancer 1993;71:3552-9.

5 Andersen J, Thorpe SM, King WJ, Rose C, Christensen I, Rasmussen BB, et al. The prognostic value of imRasmussen $\mathrm{BB}$, et al. The prognostic munohistochemilest binding assays. Eur 7 Cancer 1990;26:442-9.

6 Andersen J, Poulsen HS. Immunohistochemical analysis of estrogen receptors (ER) using formalin-fixed, paraffinembedded breast cancer tissue: Correlation with clinical endocrine response. $\mathcal{F}$ Steroid Biochem 1988;30:337-9

7 Key G, Becker MHG, Baron B, Duchrow M, Schluter C Flad HD, et al. New Ki-67-equivalent murine monoclonal antibodies (MIB-1-3) generated against bacterially expressed parts of the Ki-67 cDNA containing three 62 base pair repetitive elements encoding for the $\mathrm{Ki}-67$ epitope. Lab Invest 1993;68:629-36.

8 McCormick D, Yu C, Hobbs C, Hall PA. The relevance of antibody concentration to the immunohistological quantification of cell proliferation-associated antigens. $H$ is topathology 1993;22:543-36.

9 Cattoretti G, Becker MHG, Key G, Duchrow M, Schlutter $\mathrm{C}$, Galle J, et al. Monoclonal antibodies against re$\mathrm{C}$, Galle J, et al. Monoclonal antibodies against re-
combinant parts of the Ki-67 antigen (MIB 1 and MIB 3) combinant parts of the $\mathrm{Ki}-67$ antigen (MIB 1 and MIB 3 ) detect proliferating cells in microwave-processed form

10 Shi S, Key ME, Karla KI Antigen retrieval in formalinfixed, paraffin-embedded tissue: an enhancement method for immunohistochemical staining based on microwave oven heating of tissue sections. F Histochem Cytochem 1991 39:741-8

11 Aaltoma S, Lipponen P, Eskelinen M, Kosma VM, Marin $\mathrm{S}$, Alhave $\mathrm{E}$, et al. Hormone receptors as prognostic factors in female breast cancer. Ann Med 1991;23:643-8.

12 Helin ML, Helle MJ, Helin HJ, Isola JJ. Proliferative activity and steroid receptors determined by immunohistoand steroid receptors determined by immunohistocinomas. Arch Pathol Lab Med 1989;113:854-7.

13 Bacus SS, Goldschmidt R, Chin D, Moran G, Weinber $\mathrm{D}$, Bacus JW. Biological grading of breast cancer using antibodies to proliferating cells and other markers. $A m$ f Pathol 1989;135:783-92.

14 Siitonen SM, Isola JJ, Rantala IS, Helin HJ. Intratumor variation in cell proliferation in breast carcinoma as determined by antiproliferating cell nuclear antigen monoclonal antibody and automated image analysis. Am f Clin Pathol 1993;99:226-31.
15 Veronese SM, Gambacorta M, Gottardi O, Scanzi F, Ferrari $M$, Lampertico $P$. Proliferation Index as a prognostic marker in breast cancer. Cancer 1993;71:3926-31.

16 Gerdes J, Lelle RJ, Pickartz H, Heidenreich W, Schwarting $\mathrm{R}$, Kurtseifer $\mathrm{L}$, et al. Growth fractions in breast cancers determined in situ with monoclonal antibody $\mathrm{Ki}-67$. F Clin Pathol 1986;39:977-80.

17 Hall PA, Levinson DA, Woods AL Yu CC-W, Kellock DB Watkins JA, et al. Proliferating cell nuclear antigen (PCNA) immunolocalization in paraffin sections: an index of cell
proliferation with evidence of deregulated expression in proliferation with evidence of deregulated
some neoplasms. $\mathcal{F}$ Pathol 1990;162:285-94.

18 Andersen J, Ørntoft TF, Poulsen HS. Immunohistochemica demonstration of estrogen receptors (ER) in formalinfixed, paraffin-embedded human breast cancer tissue by use of a monoclonal antibody to ER. $\mathcal{F}$ Histochem Cytochem 1988;36:1553-60.

19 Gundersen HJG, Jensen EB. The efficiency of systematic sampling in stereology and its prediction. 7 Microsc 1987; 147:229-63.

20 Ladekarl $\mathbf{M}$. The influence of tissue processing on quantitative histopathology in breast cancer. 7 Microsc 1994; 174:93-100

21 Gundersen HJG. Notes on the estimation of the numerical density of arbitrary profiles: the edge effect. $\mathcal{f}$ Microsc

22 Sokal RR, Rohlf FJ. The principles and practice of statistics in biological research. 2nd edn. New York: W.H. Freeman, 1981 .

23 Hopwood D. Fixation and fixatives. In: Bancroft JD, Steven A, eds. Theory and practice of histological techniques. 2nd edn. Churchill Livingstone, 1982:20-40.

24 Esteban JM, Kandalaft PL, Metha P, Odom-Maryon TL, Bacus S, Battifora $\mathrm{H}$. Improvement of the quantification of estrogen and progesteron receptors in paraffin-embedded tumors by image analysis. Am 7 Clin Pathol 1993;99:32-8.

25 Verhoeven D, Bourgeois N, Derde MP, Kaufman L, Buyssens N. Comparison of cell growth in different parts of breast cancers. Histopathology 1990;17:505-9.

26 McCarty KS, Szabo E, Flowers JL, Cox EC, Leight GS, et al. Use of a monoclonal anti-estrogen receptor antibody in the immunohistochemical evaluation of human tumors. Cancer Res 1986;46(Suppl):4244S-8S

27 McCarty KS Jr, Miller LS, Cox EB, Konrath J, McCarty KS. Estrogen receptor analyses. Correlation of biochemical and immunohistochemical methods using monoclonal antireceptor antibodies. Arch Pathol Lab Med 1985; 109:716-21. 